\title{
Psychiatric stigma across cultures: Local validation in Bangalore and London
}

\section{Citation}

Weiss, Mitchell G., Sushrut Jadhav, R. Raguram, Penelope Vounatsou, and Roland Littlewood. 2001. "Psychiatric Stigma Across Cultures: Local Validation in Bangalore and London." Anthropology \& Medicine 8 (1) (April): 71-87. doi:10.1080/13648470120063906.

\section{Published Version}

doi:10.1080/13648470120063906

\section{Permanent link}

http://nrs.harvard.edu/urn-3:HUL.InstRepos:34864852

\section{Terms of Use}

This article was downloaded from Harvard University's DASH repository, and is made available under the terms and conditions applicable to Other Posted Material, as set forth at http:// nrs.harvard.edu/urn-3:HUL.InstRepos:dash.current.terms-of-use\#LAA

\section{Share Your Story}

The Harvard community has made this article openly available.

Please share how this access benefits you. Submit a story.

\section{Accessibility}




\title{
Psychiatric Stigma Across Cultures: Local Validation in Bangalore and London
}

\author{
Mitchell G. Weiss ${ }^{1}$, Sushrut Jadhav ${ }^{2}$, R. Raguram ${ }^{3}$, Penelope Vounatsou ${ }^{1}$, \\ and Roland Littlewood ${ }^{4}$
}

April 2001

\section{Submitted for publicationin Anthropology and Medicine, Special issue on Cultural Epidemiology}

\author{
Correspondence to: \\ Dr. Mitchell Weiss \\ Department of Public Health \& Epidemiology \\ Swiss Tropical Institute \\ Socinstrasse 57, \\ $\mathrm{CH}-4002$ Basel \\ Switzerland \\ E-mail: Mitchell-G.Weiss@unibas.ch
}

1. Department of Public Health and Epidemiology, Swiss Tropical Institute and University of Basel, Basel, Switzerland

2. Department of Psychiatry, University College London, London, England

3. Department of Psychiatry, National Institute of Mental Health and Neuro Sciences, Bangalore, India

4. Departments of Anthropology and Psychiatry, University College London, London, England 


\section{Abstract}

Public responses to depression have a powerful effect on patients' personal experience of illness, the course and outcome of the illness, and their ability to obtain gainful employment. Mental illness-related stigma reduction has become a priority, and to be effective, it requires innovative and effective public mental health interventions based on a clear understanding of what stigma means. Based on Goffman's formulation as spoiled identity, local concepts of stigma were validated and compared in clinical cultural epidemiological studies of depression in Bangalore, India, and London, England, using the EMIC, an instrument for studying illness-related experience, its meaning, and related behaviour. Similar indicators were validated in both centres, and the internal consistency examined to identify those that contributed to a locally coherent concept and scale for stigma. Qualitative meaning of specific features of stigma at each site were clarified from patients' prose narrative accounts. Concerns about marriage figured prominently as a feature of illness experience in both centres, but it was consistent with other indicators of stigma only in Bangalore, not in London. Although stigma is a significant issue across societies, particular manifestations may vary, and the cultural validity of indicators should be examined locally. Analysis of cultural context in the narrative accounts of illness indicates the variation and complexity in the relationship between various aspects of illness experience and stigma. This report describes an approach following from the application of cultural epidemiological methods for identifying and measuring locally valid features of stigma in a scale for baseline and followup assessment to monitor stigma reduction programmes, cultural study, and cross-cultural comparisons. 


\section{Psychiatric Stigma Across Cultures:}

\section{Local Validation in Bangalore and London}

Increasing evidence shows that social responses influence the prognosis of mental illness (Littlewood, 1998). Critical features of stigmatisation and self-perceived stigma, which clinical practice and public health policy strive to reduce, result in lack of treatment or under-treatment of psychiatric illness due to its public meaning, deferred referrals, high outpatient dropout rates, poor treatment adherence and poorer outcomes from rehabilitation programmes (Byrne, 1999). Among patients in the community, related problems include reduced self-esteem from self-stigmatisation, victimisation from physical and psychological abuse (including harassment and assault), loss of employment and job opportunities (Glozier, 1998), and housing difficulties (Byrne, 1999). With its history as a fairly diffuse sociological concept, stigma is often characterised with reference to cultural norms and values, which must be considered in assessing it, especially for cultural study and comparisons. Approaches in the context of cultural epidemiology have been developed to assess stigmatisation, both quantitatively and qualitatively, which enable researchers, clinicians, and policy makers to examine specific features of stigma locally, and which hold promise for relating stigma to other cultural, educational, and health policy variables.

Stigma reduction has recently become a major objective for national and international health policy makers, including the World Psychiatric Association, the World Federation for Mental Health, and the Royal College of Psychiatrists (Paykel et al., 1998), targeting both the general population (Crisp, 2000) and health care providers (Byrne 2000). As the work of these programmes proceeds, it becomes increasingly important to assess stigma to identify appropriate ways of reducing it, and to evaluate the results of these various efforts (Crisp et al., 2000). The consensus on stigma as a priority for population-based mental health 
programmes recognises the importance of social context as a key determinant of illness experience, course, and outcome - especially for chronic illness. Several factors motivate increased attention to this issue: (a) recognition of the value of socially empowering formerly disenfranchised groups; (b) changing indicators of global disease burden reflected by development and acceptance of the index of the disability-adjusted life-year (DALY), shifting the focus of international health from a narrow focus on childhood mortality to more comprehensive concerns that consider adult disease and disability; and (c) increased attention to chronic diseases, including mental illness, which become more prominent over the course of the epidemiological transition, as patterns of morbidity and mortality shift from infectious and parasitic diseases to non-communicable diseases in low-income countries over the course of economic development.

The sociologist Erving Goffman (1968) specified the notion of spoiled identity as an essential feature of stigma. From a professional medical and public health perspective, however, it is important to distinguish aspects of culturally motivated stigma that are either appropriate or inappropriate targets for health policy and efforts to reduce stigmatisation. Although isolation of actively infectious patients may be justifiable, such measures in the absence of justifiable risk may be regarded as stigmatising and an appropriate concern of clinical medicine and public health. In some settings, on the other hand, stigmatisation may also serve a socially valued function. For example, control of criminal behaviour, especially petty crimes for which penalties are minimal, may rely on social stigma. A code of conduct is unpersuasive if people have less regard for dishonour than the cost of behaving honourably (such as the cost of purchasing a train ticket for travel in public transport systems in which ticket checking is infrequent). Stigma that blames people with an illness or any condition for which they are blameless is another matter. While the functional capacities of patients with serious depression or other mental illness may be compromised, ignoring the benefits of 
treatment and effective control, denying opportunities based on incorrect assumptions of reduced capacities, and many other discriminatory practices are stigmatising and appropriate targets of intervention. Efforts to reduce the stigma of depression focus on the need to challenge the secrecy that prevents people from seeking treatment for it or discussing it when they do come for medical care, and which also leads doctors to politely sidestep the issue (Byrne 2000).

Attention to a cultural perspective confronts the complexity of characterising the nature of stigma, what is stigmatised, how it is stigmatised, and particular implications of stigma. It is by no means evident that different societies in which stigma is significant regard the same features as salient. The two cultures selected for the current study-Bangalore in South India and London, England - have vast differences in religion, values, social and family structure, degree of industrialisation, employment opportunities, health care, and so forth. Although comparative research on stigma in these two societies is scant, a previous study comparing social responses to people with schizophrenia, depicted in vignettes, found fewer discrediting ideas in an Indian sample in Calcutta, compared with Londoners (Littlewood, 1998). That finding is at odds with the common assumption among mental health professionals in London that stigmatisation by South Asian Britons in London is greater than by white Britons (Littlewood and Lipsedge, 1996). Perhaps the finding from research in Calcutta represents a unique feature of Bengali culture, which is considerably different from Bangalore and South India. Bengali terms applied to the people with severe mental illness in the vignettes referred to a positive aspect of religious conviction and eccentricity (McDaniel, 1989; Littlewood, 1993). In any case, since the relationship between what people say and what they do is not necessarily clear, the practical significance of this finding is difficult to know. In the current study, depression, rather than psychosis, was studied, enabling us to consider a more common clinical problem with distinctly different 
cultural meanings, and respondents were affected persons, rather than a lay population reacting to a vignette.

Other researchers have employed various methods for studying the stigma of mental illness, each with their own advantages and limitations, including (a) individual studies in the general population using questionnaires and vignettes (MacLean, 1969), (b) ethnographic accounts (Edgerton, 1966), and (c) case histories and personal narratives (Gallo, 1994). Personal accounts of the mentally ill have recently come to be regarded as especially authoritative, partly because they represent a view from the vantage point closest to the experience we would like to understand, and also because this approach to studying the question is itself destigmatising, since it acknowledges the value of the experience of the respondent. Such methods are essential for identifying the character and qualitative features of stigma, but without further refinement, they lack a capacity to exploit epidemiological power to assess and compare stigma associated with different disorders or among different social groups, or to assess change in response to programme interventions and public health policy.

\section{Methods}

The current research assessed stigma as part of a broader cross-cultural study of illness-related experience, meaning, and behaviour, using locally adapted instruments for cultural epidemiology known as the EMIC (Weiss, 1997; Weiss et al., 1992; Jadhav 1999). The EMIC is not a fixed scale, but rather a framework for flexible interviews elaborating patterns of distress, perceived causes, and help-seeking behaviour. These interviews elicit narrative responses for categorical coding, distinguishing spontaneous and probed responses. A database of narrative responses facilitates qualitative analysis. Questions to characterise patterns of distress examined self-perceived stigma, making use of parameters suggested by 
Goffman, especially the social consequences of disclosure and stigma conceptualised as a social process. Items considered for inclusion in the assessment required verification and cultural validation from ethnographic fieldwork in the local setting and pilot testing of interview items.

Randomly selected patients presenting for treatment with clinical diagnoses of ICD-9 Neurotic Depression were studied at the National Institute of Mental Health and Neuro Sciences, Bangalore, and in outpatient and inpatient NHS psychiatric services of Camden and Islington boroughs in London. Patients represented predominant South Indian cultures in Bangalore (Hindus and Muslims) and white British majority culture in London.

Both of the principal field researchers (SJ and RR) were psychiatrists trained in social science. In London, a panel of mental health professionals and advocacy groups was consulted, community leaders were interviewed, the health care system was examined in the course of participant observation, and mental health policy-related content was extracted from media scanning. In Bangalore, preparatory work included examining local Ayurvedic texts, interviews with mental health professionals, participant observation, local community interviews, and media scanning (Raguram et al., 1996).

Questions about illness-related experience, meaning, and behaviour were included in the local adaptation of the EMIC at each centre (Jadhav, 1999; Raguram et al., 1996). Items for assessment of stigma were initially regarded as tentative and subsequently validated with reference to internal consistency and coverage of relevant issues. The research aimed to ensure validation of a locally coherent concept of stigma based on mutually consistent indicators. Because the number of items was determined by the number of items validated, rather than a fixed number at the outset, comparison of the two groups was based on the percent of theoretical maximum scores at each site, rather than raw scores; the analysis also examined qualitative aspects of stigma in patients' narrative accounts. 


\section{Results}

\section{Quantitative approach}

In Bangalore 80 patients were interviewed, and 47 in London. Questions about disclosure and other indicators of stigma under consideration were coded with values from 0 to 3 indicating denial, uncertainty, the possibility, or definite of each item (or rejection if reverse-coded). Values for each item were combined additively in a scale, each item with equal weight. At the outset 11 items were considered in the London study and 12 items in the Bangalore study. Results from each study are summarised in table $\mathbf{1 .}$

\section{[Table 1 about here]}

Calculation of Cronbach's alpha and the correlation of each item to the total were used to assess the internal consistency of the items and their suitability for use in a scale. Items that were incompatible with the locally coherent conceptualisation of stigma were eliminated (Tables 2 and 3). The Cronbach's alpha statistic is based on the inter-average correlation of items, a value of 1 indicating perfect intercorrelation and a value of 0 indicating no intercorrelation whatsoever. Items that detracted from the internal coherence of the scale - that is, their deletion increased the value of alpha—-were deleted from the scale only if their item-to-total correlation was less than 0.2 , so as to maintain justifiable coverage of the scale (Tables 2 and 3). We initially adopted this rule of thumb, recognising that the increase from a deleted item is not necessarily statistically significant and items should not be dropped without due consideration. This hypothesis may be tested by considering the probability that the increase in alpha from dropping an item is statistically significant.

Five items were retained in the London adaptation and 11 items in the Bangalore adaptation, with theoretical maximum scores of 15 and 33, respectively. Items in both of the 
scales focussed on the stigma of the specified problem, rather than isolated symptoms, in this analysis. This method, based on additional experience studying stigma in other cultural epidemiological studies, refines the approach used initially for analysis of stigma in the Bangalore data set (Raguram et al., 1996).

\section{[Tables 2 and 3 about here]}

Having identified locally distinctive, mutually consistent features of stigma in both sites, a comparison between the two, based on the percentage of the local theoretical maximum score, indicated a higher level of self-perceived stigma in the London sample (Table 4).

\section{[Table 4 about here]}

Greater concerns about disclosure and being burdensome to others in London contributed to these higher levels of stigma.

\section{Qualitative meaning}

In addition to coding responses according to precoded categories for quantitative analysis, we also included narratives to elaborate the context and details of these responses in a qualitative data set. We examined the narrative accounts from the responses of subjects whose stigma scores were in the upper quartile to clarify the meaning of stigma at each site. This approach enabled us to consider not only the magnitude of stigma and its locally important manifestations, but also the particular ways in which these issue concern and affect patients. 


\section{Bangalore}

Narrative accounts of stigma among patients in the Bangalore sample focussed on concerns about respectability and status in society. People rely on their social standing and being connected in social networks. Social esteem is valued highly, both as a determinant of self-esteem, and as a prerequisite for the self-respect required to function effectively in the community. Losing that social standing may be experienced as blameworthy and incapacitating. A 48 year-old woman described these concerns as follows:

My brother said I am suffering because I have done some karma [deed] in my life. Everyone in my family looks down on me, saying I am suffering from my own karma. For some people, my problem should not be revealed, I feel. They tease me or criticise me.

Because social standing is a crucial determinant of power and weakness, illness and suffering are to some extent matters of concern insofar as they enhance vulnerability to manipulation and control in any dispute. A middle-aged woman with depression told us, "Some people should not come to know about my problems, as they are against us in the village."

Cultural values associated with dharma (a complex concept that encompasses traditional norms of conduct) in India emphasise the importance of various duties and obligations that are characteristic features of complex societies and cultures. These concerns were especially compelling for the patients in the Bangalore sample. Inability to fulfill family and social obligations were a distressing feature of illness, and a shortcoming that others should not know about. "People might think I don't obey my parents," a 22 year-old Brahmin woman who was studying to be a secretary told us as she related concerns about her illness. "They would look down on me." Some patients preferred not to disclose too much even to close relatives within the family. A professionally trained young man with a diploma in mechanical engineering explained, "I have not told anyone about these problems; my mother 
asks me about being dull these days, but she does not know all about my feelings. I don't want anyone to know."

Inasmuch as it may also yield valued benefits, however, disclosure was not a matter of all-or-none. In an effort to regulate the damage that may follow from social disclosure, and yet recognising the need for some degree of support that they hoped discussing their problems might provide, some patients only disclosed specific features of their problems. It was easier to reveal concerns about specific symptoms, especially somatic symptoms, without disclosing the full magnitude of suffering. A 48 year-old housewife provides an example of how carefully some people considered what could be and should not be disclosed:

My son, daughter, and brother-in-law all know about these crawling sensations. But my being sad, I have told only my brother's wife. I have told everything to my younger brother's wife; she understands my feelings, but no one else. My children know about my bodily problem, the crawling sensation. I did not want my brother-in-law to know about my problems. They know my children are not having contact with me, and so they may talk, that this may be because of some sin I have done. Neighbours know about crawling sensation, but not about my mental feelings.

In addition to these relatives to whom this woman has disclosed her problem in varying degrees of detail, and desiring the anticipated benefit that further disclosure beyond that might provide, she explained: "I would like to express to someone close to me all about me; but I don't have anyone close to me who can listen."

Although inhibiting disclosure typically resulted from shame and concern that it would diminish social standing, for some the reluctance to disclose arose from other reasons, including the pain it might inflict on the person to whom they disclosed, in most cases a spouse. Typically it was men who expressed these concerns. A 39 year-old man, who worked 
as a veterinary inspector and was distressed after being transferred from Bangalore city to a rural posting, explained, "My wife knows everything, but still I have not told how much tension I have inside, because she becomes so upset if she knows completely about my problems." A 25 year-old Muslim man, who drives a tempo (three-wheeler taxi) for a living, told us, "I would tell my wife about my sadness, but she would feel sad, so I don't tell." It wasn't only spouses, however, who were considered vulnerable to the burden of disclosure. A young woman, who assists with the family's printing business, and who remained dependent on support from her father because of marital conflicts, explained, "I used to tell my father, but after he got a heart attack, I stopped telling, because doctors said he should take complete rest."

As expected, the focus on the adverse social impact of disclosure and the importance of arranging marriages in Indian society made various aspects of marriage a focus of concern and key components of stigma in Bangalore. People feared that if it were widely known that they were troubled by emotional problems, it would be difficult to arrange a marriage. They were also concerned about the impact of their illness on prospects for arranging a relative's marriage, and to a lesser extent how their problems might affect their own ongoing marriage. Women were especially vulnerable to this aspect of social stigma. A 39 year-old woman had a stillbirth, which some people suggested might have been caused by her bezaar kayile (despondency illness). Later, after the death of her first husband, she had difficulty with her in-laws and had to leave their home without money or property, but still she managed to remarry and hoped to again regain a normal life. The sadness returned with greater intensity, and she explained how she now thinks it would affect marriage:

No one would marry me if I had this bezaar kayile. This sadness has also affected our smooth [marital] relationship. We quarrel many times... He may 
leave me because we cannot understand each other. If he wants a child, I don't cooperate.

Another middle-aged woman from an agricultural family, who initially had difficulty speaking about her problems, explained as she sat at the table, resting her head on her arms and smiling, that it was the fact of being sick, without discussing the effect on relationships: "I never took even one tablet before marriage. I never had any problem. How could I get married with this kayile?" And the young woman, mentioned above, who was studying to be a secretary, explained: "No one would agree to marry me if I am having sad face all the time. Who would accept me?"

Not only were features of the illness were socially unacceptable, they also made it difficult to mobilize the social networks required for the family work of arranging a marriage. Explaining how these symptoms took their toll on an ongoing marriage and compromised the ability of relatives to marry, this same young woman continued, “As I can't mingle with others, it is because of that my marital life would have been affected... It would also have been a problem if I had a sister to marry.”

The perceived impact of social stigma on the ability to marry was even more prominent as a concern about the ability of a relative to marry. "Yes, people talk like that; they will say, the mother had that disease, how can we marry her daughter," a middle-aged woman from a land-owning family explained. Another woman from a respected family - the wife of a headmaster, sister of a veterinarian, and daughter of a priest —explained, "Thank God that he did not give me daughters; it would have been a problem for them to get married, because I cannot marry them due to many reasons." For others it was not just the social stigma but also impaired ability to make all the necessary arrangements required to arrange a daughter's marriage. "Yes, I have all these aches and pains, so I am not able to see boys for 
my daughters and get them married. My husband does not take care of their marriage, so I feel like that."

Men spoke less about social disapproval based on their condition than about their compromised ability to provide for family, as they were expected to do. A 22 year-old man from a low-caste community who had studied through the $10^{\text {th }}$ standard, but did not pass his examination for diploma, explained, "Who would marry me if I cannot hold a job or earn money?" For some patients it was not so much that others would not accept them because they could not fulfill responsibilities as providers, but rather the fact that they themselves found the situation intolerable. For these men, it was not so much a matter of who would want them, but rather they would not like the responsibilities of marriage that they feared they could not fulfill.

\section{London}

In the London sample some patients readily identified stigma by name as a problem, and one man provided an articulate account of what it meant for him. This 27 year-old unemployed labourer, who had been suffering from symptoms of depression for the past 10 years, explained:

Yes, I have told a lot of people, but it sounds like a script.... I meet people and don't know what they know. If they know, they treat you differently. They are a bit more guarded. People are afraid of mental illness or depression, or whatever you would like to call it. People are afraid of what is inside themselves.... People are very wary of people with extreme behaviours or emotions. I have spoken to people and spoken quite openly. I spoke with someone at a party, and I told him what I am doing and what kind of voluntary work I do and, umm, it took him about two minutes to walk away afterwards, 
after I told him, and we had just spoken for ages. He just kind of got up and really left. So there is a stigma.

Narrative accounts of illness experience among the British patients often focussed on intolerance of weakness and concern about being a burden to others. Items representing these concerns were key features in the locally validated British stigma scale, and the story of a man who had been an entrepreneur and had also managed a casino, indicated the nature of these concerns:

"There is a lot of stigma attached to problems, particularly anxiety, and anything else that you cannot cope with. Things that make people perceive you as being weak. Weakness is not tolerated in British society."

He explained how he felt that this feature of British society had affected him personally. 'I didn't go back to my brother, because I didn't want to be a burden on him, especially when he has four young children. I didn't want to have any influence on their development."

A psychiatric nurse, currently unemployed, who liked to watch soap operas, was interviewed a few days before her $32^{\text {nd }}$ birthday. She explained, "My mother has worries of her own. This is just one extra thing that she can do without." When asked how she contributes to those worries, she said, "I suppose when I get desperate and hopeless, and I just think, you know, I threaten to discharge myself because I can't see any future, then obviously it upsets them."

This concern about showing weakness and its repercussions accentuated concerns about disclosure. People were afraid not just about worrying them, but that if their friends found out, these friendships would not survive. A man reported, "I have lost so many friends because of my depression, you know. I am left with one and one only. He suffers from manicdepression; he understands." Like another man who explained he would be able to disclose 
his problems more easily to another psychiatric patient, those who were recognised as sharing the same weakness and vulnerabilities were expected to be more tolerant and better able to provide desired support for what patients regarded as a socially stigmatising problem.

Although weakness was a devalued experience whilst strength was valued, associations between mental illness and inappropriate aggression created a dilemma for some patients. It seemed to them that their illness compromised their ability to assert themselves in the ways that were considered normal and appropriate for others. "I have always been passive," a woman explained, and she continued:

"If I stand up and try to be assertive, it may be mistaken as aggressive, and taken as a symptom, not just an ordinary outburst. People will immediately sort of think, 'Oh, she's not well again.' That's what I am afraid of. I feel that because of the nature of things, I have to keep up an appearance of being okay all the time."

The illness did not absolve responsibility for fulfilling the requirements of cultural ideals, and it made it more difficult to do so, thereby enhancing the self-perceived stigma among these patients affected by depression.

\section{Discussion}

The approach to the study of stigma — both its magnitude and meaning — indicates the importance of locally validating the concept in cultural context. Although this technique is illstrated by the Bangalore data set, the smaller sample size and perhaps other factors made it difficult to achieve the same level of internal consistency among the possible indicators of stigma that were considered. The lower value of the alpha statistic for the stigma scale from the British sample compared with the Indian sample may reflect the smaller sample size in London. The possibility that stigma is a more diffuse, somewhat idiosyncratic, concept 
among the British, and the possibility that other items not considered in this study might also have been relevant to the experience of stigma must also be considered. For example, opportunities for employment, education, housing, health care, and community participation should be considered in more comprehensive studies of stigma (Glozier, 1998).

The most striking feature in the differences between the two scales was the absence of self-reported concerns about marriage in the London sample. It is not that these were not matters of concern - in fact they were, and a matter of more concern to more of the respondents in London than in Bangalore. But these concerns were not reported in a manner consistent with other aspects that constituted a more coherent concept of stigma for the London sample, in which restricted disclosure and the burden on others was emphasised. In Bangalore, on the other hand, marital issues (viz. the ability to get married, to arrange a relative's marriage, and problems caused by the illness in the current marriage) were an anticipated aspect of stigma, and they were consistent with other aspects of stigma, as they had also been in African studies employing a similar approach (Vlassoff et al., 2000). The role of marriage in a locally coherent conceptualisation of stigma appears to be different in London, possibly reflecting different cultural values.

It should also be borne in mind, that our interviews with affected persons considered only self-perceived effects — based on anticipated consequences, fears, and hopes — rather than comparing statistics that reflect actual opportunities for marriage and the impact of illness on making and breaking marital alliances. To go beyond self-report, such data must be obtained in other ways, and typically from other sources. Consequently, the question of whether or not stigma of mental illness (or anything else) actually affects the stability of marriages and the ability to marry is another matter, distinct from the question of selfperceived effects of illness on marriage. 
When the British patients spoke of them, questions about marriage and related concerns evoked responses that often concerned boyfriends and girlfriends, rather than spouses. Marriage for the British is a matter of choice, rather than family arrangement, and when questions of the impact of illness on marriage arose, it was an issue of whether the partner was willing, rather than whether the families would permit it. "My ex-boyfriend said he didn't want to marry me," a young women explained. For some people, however, the appeal of marriage was the idealised intimacy it promised with a safe and trustworthy partner. Wanting to achieve such a goal, yet unsure how much personal history the desired relationship could tolerate, a British woman respondent characterised the dilemma: "If I had a chance to marry, I wouldn't tell someone unless they were another psychiatric patient. But I wouldn't get married without having mentioned it and then have things fall to bits if they found out later."

The British patients were not so much concerned about the effects of their illness on a relative's marriage. Because many of them do not regard families as cohesive and stable entities to begin with, concerns about disrupting cohesion and stability were less of an issue. A British man explained to his Indian interviewer, "Families don't stay together. People move away and find their own thing. I guess that is a peculiarly Western thing." Some suggested that their depression was not a socially stigmatised concern, suggesting how they considered it different from a clear-cut genetic condition: "We don't have that concern here. My problem wouldn't affect my sister's relationship. But maybe if you have a situation where the brother is schizophrenic or something-I have heard that some people go in for genetic counselling. I have seen things; some people are kind of wary.” A woman elaborated the same point, explaining there was no problem for relatives to marry: "No, my illness isn't hereditary. If it were schizophrenia and there was a couple of brothers, then I suppose people would be concerned-schizophrenia or a psychopath." 
Self-perceived stigma was notably higher in the London group. Several factors may explain this finding: (a) The London sample included inpatients, and some of the outpatients came to treatment after emergency admission through the casualty ward. Inpatient and emergency treatment may be more stigmatising.

(b) Because they value autonomy and are less likely to involve family and other caretakers in their treatment than Indian patients, disclosure may have been a matter of greater concern for the Londoners; the importance placed on protecting confidentiality may at once reflect and contribute to stigma. We know also from analysis of both the Bangalore and London data that an emphasis on emotional symptoms and psychologically rooted perceived causes is associated with greater stigma, and a somatic emphasis is associated with less stigma (Jadhav, 1999; Raguram et al., 1996). Other research, including studies of chronic fatigue syndrome in Britain and North America, also indicates that somatic medical explanations tend to be less stigmatised (MacLean and Wesseley, 1994). The Bangalore group emphasized somatic symptoms, and the London group emphasized psychological aspects of the experience and the meaning of their illness.

(c) A third factor explaining the greater magnitude of stigma in the London sample may be an artefact arising from differences in the items that were considered in the London sample. Two questions are similar, "Does your problem make you a burden with adverse effects on others?" and "Are your emotions and feelings upsetting to others?" Only the former of these items was included in the Bangalore interview, and the results in London show that responses were similar for both items, which are conceptually similar. Since the scale was constructed with all items having equal weight, the version used in London may have given double weight to the same or very closely related concept.

Greater attention to the social contexts of illness and suffering have focussed attention and the concern of public health policy on the question of stigma. If programmes to reduce 
stigma are to be relevant and effective, they must acknowledge and address the cultural underpinnings of stigma. Unlike most epidemiological and psychometric instruments, which aim to produce fixed scales and standardised measures for use in diverse settings, culturally valid instruments may be more useful for some purposes if they permit local adaptation. The ability to measure stigma in a manner that accounts for such varied manifestations and cultural specificity provides a way of testing hypotheses about the sources and effects of stigma with reference to other cultural, clinical, and demographic variables.

Without attention to local validation acknowledging culture-specific features of stigma, research cannot shape interventions and assess their impact effectively. Comparing stigma across cultures with scales comprising different items is more complicated than standard epidemiological comparisons. Nevertheless, by considering percentage of maximum scale scores and qualitative features of stigma from narrative accounts of respondents, as indicated in this report, such assessments integrating anthropological principles in a cultural epidemiology are more likely to capture the essential features of stigma, and they are more likely to be both valid and useful. This makes it possible to understand the magnitude, changes, and cultural differences in the cultural construction of stigma. The analysis of the social context in the narrative accounts of stigma-related illness experience in response to focussed queries provides complementary information that indicates the nature of what the issues that contribute to a coherent concept of stigma, what they means, and how they affect people's lives. It is only through an appreciation of this complex relationship between stigma and context that efforts to reduce stigma can address the core issues that have made it a high priority in public health policy for mental illness and other health problems for which the impact of stigma is a critical matter of policy.

\section{Acknowledgement}


Discussion of the cultural basis and assessment of stigma at the Workshop on Cultural Epidemiology and Experience with the EMIC at the Swiss Tropical Institute, 21-25 February 2000, contributed to the development of this article. Support from the Swiss National Science Foundation, Grant \#32-51068.97, Cultural Research for Mental Health, is gratefully acknowledged. 


\section{References}

Byrne, P. Stigma of mental illness and ways of diminishing it. Advances in Psychiatric Treatment, 2000; 6: 65-72

Byrne, P. Stigma of mental illness: changing minds, changing behaviour. Br J Psychiatry, 1999; 74: 1-2

Crisp, A.H., Gelder, M.G., Rix, S., Meltzer, H.I., Rowlands, O.J. Stigmatisation of people with mental illnesses. Br J Psychiatry, 2000; 177: 4-7

Crisp, A. Changing minds: every family in the land. Psychiatric Bulletin, 2000; 24: 267-268

Edgerton, R.B. Conceptions of psychosis in four East African societies. Am Anthropologist, 1966; 66: 408-425

Gallo, K.M. Self-stigmatisation. Schizophrenia Bulletin, 1994; 20: 407-410

Glozier, N. Workplace effects of the stigmatisation of depression. J Occupational and Environmental Med, 1998; 40: 793-800

Goffman, E. Stigma: Notes on the Management of Spoiled Identity. Harmondsworth: Penguin, 1968

Jadhav, S. The Cultural Experience of Depression among White Britons in London. Ph.D. thesis 1999, University College London

Littlewood, R. and Lipsedge, M. Aliens and Alienists: ethnic minorities and psychiatry. Third edition, London: Routledge, 1996

Littlewood, R. Pathology and Identity. Cambridge: Cambridge University Press, 1993

Littlewood, R. Cultural variation in the stigmatisation of mental illness. Lancet, 1998; 352: $1056-1057$

Maclean, V. Community attributes to mental illness in Edinburgh. B Prev Soc Med, 1969; 23: $45-52$ 
MacLean, G., Wesseley, S. Professional and popular views of chronic fatigue syndrome. BMJ, 1994; 308: 776-777

McDaniel, J. The Madness of Saints: Ecstatic Religion in Bengal. Chicago: University of Chicago Press, 1989

Paykel, E.S., Hart, D., Priest, R.G. Changes in public attitudes to depression during the Defeat Depression Campaign. Br J Psychiatry, 1998; 173: 519-527

Raguram, R., Weiss, M.G., Channabasavanna, S.M., Devins, G.M. Stigma, depression and somatisation: a report from South India. Am J Psychiatry, 1996; 153: 1043-1049

Vlassoff, C., Weiss, M., Ovuga, E.B.L., Eneanya, C., Nwel, P.T., Babalola, S.S., et al. Gender and the stigma of onchocercal skin disease in Africa. Soc Sci Med, 2000; 1353-1368

Weiss, M.G., Doongaji, D.R., Siddhartha, S., Wypij, D., Pathare, S., Bhatawdekar et al. The Explanatory Model Interview Catalogue (EMIC): contribution to cross-cultural resource methods from a study of leprosy and mental health. Br J Psychiatry, 1992; 160: $819-830$

Weiss, M. The Explanatory Model Interview Catalogue (EMIC): a framework for the comparative study of illness. Transcultural Psychiatry, 1997; 160, 819-830 
Tables and Figures 
Table 1. Responses to possible indicators of stigma in Bangalore and London

\begin{tabular}{|c|c|c|c|c|c|c|}
\hline \multirow{2}{*}{ Indicators considered } & \multicolumn{3}{|c|}{$\begin{array}{c}\text { London }(\mathrm{N}=47) \\
\%\end{array}$} & \multicolumn{3}{|c|}{$\begin{array}{c}\text { Bangalore }(\mathrm{N}=80) \\
\%\end{array}$} \\
\hline & Definite & Possible & Uncertain & Definite & Possible & Uncertain \\
\hline $\begin{array}{l}\text { 1. Problem known to someone you } \\
\text { preferred not to know }\end{array}$ & $46.8 \%$ & $0.0 \%$ & $2.1 \%$ & $15.0 \%$ & $0.0 \%$ & $2.5 \%$ \\
\hline $\begin{array}{l}\text { 2. Someone knows about the } \\
\text { problem, but it doesn't matter }\end{array}$ & $44.7 \%$ & $0.0 \%$ & $4.3 \%$ & $40.0 \%$ & $0.0 \%$ & $3.8 \%$ \\
\hline $\begin{array}{l}\text { 3. There is someone in particular who } \\
\text { should not know about the problem }\end{array}$ & & & & $28.8 \%$ & $17.5 \%$ & $6.3 \%$ \\
\hline $\begin{array}{l}\text { 4. Think less of yourself because of } \\
\text { the problem }\end{array}$ & $85.1 \%$ & $2.1 \%$ & $0.0 \%$ & $73.8 \%$ & $2.5 \%$ & $1.3 \%$ \\
\hline $\begin{array}{l}\text { 5. Problem is a burden, troublesome, } \\
\text { or has bad effects on others }\end{array}$ & $87.2 \%$ & $0.0 \%$ & $0.0 \%$ & $2.5 \%$ & $10.0 \%$ & $1.3 \%$ \\
\hline $\begin{array}{l}\text { 6. Emotions and feelings upsetting } \\
\text { others }\end{array}$ & $89.4 \%$ & $2.1 \%$ & $0.0 \%$ & & & \\
\hline $\begin{array}{l}\text { 7. Neighbours, colleagues, and others } \\
\text { think less of you because of your } \\
\text { problem }\end{array}$ & $66.0 \%$ & $8.5 \%$ & $8.5 \%$ & $27.5 \%$ & $5.0 \%$ & $5.0 \%$ \\
\hline $\begin{array}{l}\text { 8. Neighbours, colleagues, and others } \\
\text { think less of your family because of } \\
\text { your problem }\end{array}$ & & & & $7.5 \%$ & $3.8 \%$ & $3.8 \%$ \\
\hline $\begin{array}{l}\text { 9. Problem would make it difficult for } \\
\text { you to marry }\end{array}$ & $68.1 \%$ & $6.4 \%$ & $6.4 \%$ & $57.5 \%$ & $6.3 \%$ & $11.3 \%$ \\
\hline $\begin{array}{l}\text { 10. Problem would cause trouble in } \\
\text { marital life }\end{array}$ & $68.1 \%$ & $8.5 \%$ & $10.6 \%$ & $28.8 \%$ & $11.3 \%$ & $7.5 \%$ \\
\hline $\begin{array}{l}\text { 11. Problem would make it difficult for } \\
\text { someone else in your family to } \\
\text { marry }\end{array}$ & $14.9 \%$ & $2.1 \%$ & $10.6 \%$ & $11.3 \%$ & $2.5 \%$ & $2.5 \%$ \\
\hline $\begin{array}{l}\text { 12. Told somebody you want to know } \\
\text { about the problem (reverse code) }\end{array}$ & $12.8 \%$ & $0.0 \%$ & $2.1 \%$ & $21.3 \%$ & $0.0 \%$ & $0.0 \%$ \\
\hline $\begin{array}{l}\text { 13. Have not yet told someone you } \\
\text { want to know about the problem }\end{array}$ & $31.9 \%$ & $0.0 \%$ & $2.1 \%$ & $17.5 \%$ & $0.0 \%$ & $3.8 \%$ \\
\hline
\end{tabular}


Table 2. Indicators of stigma in London and Bangalore: Variables considered and retained in local scales

\begin{tabular}{|c|c|c|c|c|}
\hline \multirow{2}{*}{ Indicator } & \multicolumn{2}{|c|}{ Bangalore } & \multicolumn{2}{|c|}{ London } \\
\hline & Considered & Retained & Considered & Retained \\
\hline $\begin{array}{l}\text { 1. Problem known to someone you } \\
\text { preferred not to know }\end{array}$ & $x$ & $x$ & $x$ & $x$ \\
\hline $\begin{array}{l}\text { 2. Someone knows about the } \\
\text { problem, but it doesn't matter }\end{array}$ & $x$ & & $x$ & \\
\hline $\begin{array}{l}\text { 3. There is someone in particular } \\
\text { who should not know about the } \\
\text { problem }\end{array}$ & $x$ & $x$ & & \\
\hline $\begin{array}{l}\text { 4. Think less of yourself because of } \\
\text { the problem }\end{array}$ & $x$ & $x$ & $x$ & $x$ \\
\hline $\begin{array}{l}\text { 5. Problem is a burden or has bad } \\
\text { effects on others }\end{array}$ & $x$ & $x$ & $x$ & $x$ \\
\hline $\begin{array}{l}\text { 6. Emotions and feelings upsetting } \\
\text { others }\end{array}$ & & & $x$ & $x$ \\
\hline $\begin{array}{l}\text { 7. Neighbours, colleagues, and } \\
\text { others think less of you because } \\
\text { of your problem }\end{array}$ & $x$ & $x$ & $x$ & $x$ \\
\hline $\begin{array}{l}\text { 8. Neighbours, colleagues, and } \\
\text { others think less of your family } \\
\text { because of problem }\end{array}$ & $x$ & $x$ & & \\
\hline $\begin{array}{l}\text { 9. Problem would make it difficult for } \\
\text { you to marry }\end{array}$ & $x$ & $x$ & $x$ & \\
\hline $\begin{array}{l}\text { 10. Problem would cause trouble in } \\
\text { marital life }\end{array}$ & $x$ & $x$ & $x$ & \\
\hline $\begin{array}{l}\text { 11. Problem would make it difficult for } \\
\text { someone else in your family to } \\
\text { marry }\end{array}$ & $x$ & $x$ & $x$ & \\
\hline $\begin{array}{l}\text { 12. Told somebody you want to know } \\
\text { about the problem (reverse code) }\end{array}$ & $x$ & $x$ & $x$ & \\
\hline $\begin{array}{l}\text { 13. Have not yet told someone you } \\
\text { want to know about the problem }\end{array}$ & $x$ & $x$ & $x$ & \\
\hline $\begin{array}{l}\text { Cronbach's alpha (standardised } \\
\text { variables) }\end{array}$ & .71 & .73 & .40 & .62 \\
\hline
\end{tabular}


Table 3. Indicators of stigma: analysis of internal consistency and coverage of local scales*

\begin{tabular}{|c|c|c|c|c|c|c|c|c|c|c|c|c|}
\hline \multirow{3}{*}{ Indicators considered } & \multicolumn{8}{|c|}{ London ( $\mathrm{N}=47)$} & \multicolumn{4}{|c|}{ Bangalore $(\mathrm{N}=80)$} \\
\hline & \multicolumn{2}{|c|}{$\begin{array}{c}11 \text { items } \\
\text { considered }\end{array}$} & \multicolumn{2}{|c|}{$\begin{array}{c}7 \text { items } \\
\text { considered }\end{array}$} & \multicolumn{2}{|c|}{$\begin{array}{c}6 \text { items } \\
\text { considered }\end{array}$} & \multicolumn{2}{|c|}{$\begin{array}{l}5 \text { items } \\
\text { retained }\end{array}$} & \multicolumn{2}{|c|}{$\begin{array}{c}12 \text { items } \\
\text { considered }\end{array}$} & \multicolumn{2}{|c|}{$\begin{array}{l}11 \text { items } \\
\text { retained }\end{array}$} \\
\hline & $\begin{array}{c}\alpha \\
\text { w/o } \\
\text { item }\end{array}$ & $\begin{array}{c}\text { Corr } \\
\text { to } \\
\text { total }\end{array}$ & $\begin{array}{c}\alpha \\
\text { w/o } \\
\text { item }\end{array}$ & $\begin{array}{l}\text { Corr } \\
\text { to } \\
\text { total }\end{array}$ & $\begin{array}{c}\alpha \\
\text { w/o } \\
\text { item }\end{array}$ & $\begin{array}{l}\text { Corr } \\
\text { to } \\
\text { total }\end{array}$ & $\begin{array}{c}\alpha \\
\text { w/o } \\
\text { item }\end{array}$ & $\begin{array}{c}\text { Corr } \\
\text { to } \\
\text { total }\end{array}$ & $\begin{array}{c}\alpha \\
\text { w/o } \\
\text { item }\end{array}$ & $\begin{array}{l}\text { Corr } \\
\text { to } \\
\text { total }\end{array}$ & $\begin{array}{c}\alpha \\
\text { w/o } \\
\text { item }\end{array}$ & $\begin{array}{c}\text { Corr } \\
\text { to } \\
\text { total }\end{array}$ \\
\hline 1. Problem known to someone you preferred not to know & 0.29 & 0.36 & 0.51 & 0.32 & 0.56 & 0.30 & 0.60 & 0.28 & 0.68 & 0.45 & 0.71 & 0.39 \\
\hline 2. Someone knows about the problem, but it doesn't matter & 0.48 & -0.15 & & & & & & & 0.73 & 0.09 & & \\
\hline 3. There is someone in particular who should not know about the problem & & & & & & & & & 0.70 & 0.32 & 0.72 & 0.32 \\
\hline 4. Think less of yourself because of the problem & 0.32 & 0.30 & 0.50 & 0.32 & 0.55 & 0.33 & 0.58 & 0.33 & 0.69 & 0.40 & 0.70 & 0.41 \\
\hline 5. Problem is a burden or has bad effects on others & 0.33 & 0.27 & 0.53 & 0.26 & 0.57 & 0.28 & 0.60 & 0.29 & 0.69 & 0.36 & 0.71 & 0.36 \\
\hline 6. Emotions and feelings upsetting others & 0.33 & 0.27 & 0.48 & 0.40 & 0.47 & 0.52 & 0.47 & 0.53 & & & & \\
\hline $\begin{array}{l}\text { 7. Neighbours, colleagues, and others think less of you because of your } \\
\text { problem }\end{array}$ & 0.29 & 0.36 & 0.47 & 0.42 & 0.52 & 0.41 & 0.53 & 0.43 & 0.68 & 0.45 & 0.70 & 0.46 \\
\hline $\begin{array}{l}\text { 8. Neighbours, colleagues, and others think less of your family because of } \\
\text { your problem }\end{array}$ & & & & & & & & & 0.69 & 0.40 & 0.70 & 0.43 \\
\hline 9. Problem would make it difficult for you to marry & 0.37 & 0.15 & 0.60 & 0.08 & & & & & 0.68 & 0.42 & 0.70 & 0.43 \\
\hline 10. Problem would cause trouble in marital life & 0.37 & 0.15 & 0.55 & 0.21 & 0.62 & 0.17 & & & 0.70 & 0.29 & 0.72 & 0.31 \\
\hline 11. Problem would make it difficult for someone else in your family to marry & 0.44 & -0.04 & & & & & & & 0.67 & 0.49 & 0.69 & 0.51 \\
\hline 12. Told somebody you want to know about the problem (reverse code) & 0.40 & 0.07 & & & & & & & 0.71 & 0.24 & 0.73 & 0.24 \\
\hline 13. Have not yet told someone you want to know about the problem & 0.45 & -0.06 & & & & & & & 0.71 & 0.25 & 0.72 & 0.26 \\
\hline Cronbach's Alpha: standardized value for items considered & \multicolumn{2}{|c|}{0.40} & \multicolumn{2}{|c|}{0.56} & \multicolumn{2}{|c|}{0.60} & \multicolumn{2}{|c|}{0.62} & \multicolumn{2}{|c|}{0.71} & \multicolumn{2}{|c|}{0.73} \\
\hline
\end{tabular}

${ }^{*}$ Cells for each item specify the value of Cronbach's alpha with that item deleted and the correlation of that item to the total score. Values in bold indicate an item detracts from internal consistency and does not contribute to overall coverage of the scale (alpha higher with item deleted, and the item-to-total correlation less than 0.2) 
$-28-$

Table 4. Comparison of stigma in London and Bangalore

\begin{tabular}{|l|c|c|c|c|c|}
\hline \multirow{2}{*}{ Site } & \multicolumn{4}{|c|}{ Stigma scale scores (percentage of theoretical maximum) } \\
\cline { 2 - 6 } & Median* & Mean & Std dev & Min & Max \\
\hline Bangalore $(n=80)$ & 27 & 31.4 & 19.9 & 0 & 85 \\
\hline London $(n=47)$ & 80 & 77.4 & 23.1 & 20 & 100 \\
\hline
\end{tabular}

${ }^{*} \mathrm{p}<.0001$, Kruskal-Wallis test. 